Slight hydrogenation of the fat has been found of value in the case of a number of foodstuffs : it prevents rancidity in tallow and lard; it stabilises the fat in butter without destroying its flavour; it bleaches palm oil without hardening it; and finally, in the case of cacao-butter, it prevents the 'blooming' of chocolates.

Morgan, Field and Nichols have found that the vitamin $\mathrm{C}$ content of prunes and apricots need not be reduced by dehydration or treatment with sulphur dioxide when the processes are carried out under properly controlled conditions. Clow and Marlatt state that the vitamin $\mathrm{C}$ content of tomatoes is the same whether ripening occurs in the field, in the greenhouse or is brought about artificially with the aid of ethylene. It has been shown by Kohman, Eddy and Zall that considerable loss of vitamin $\mathrm{C}$ and some loss of vitamin B occur in the canning of tomatoes in the presence of air : in steam this loss is not observed. Vitamin $\mathrm{A}$ is the most, and vitamin $\mathrm{C}$ the least stable. To preserve the vitamins it is essential to guard against oxidation during canning.

Morris and Bryan have found that the method of manufacture of steel may have a considerable influence on its rate of corrosion. In solutions of low acidity the main points of attack are the pits and seams of the tin, whilst in those of high acidity, the exposed portions of the tin are particularly liable to corrosion. It is recommended that citric acid be added to fruit of low acidity, that the sugar used be free from sulphur compounds (which have a considerable influence on the corrosion of tins) and that beet sugar be used, or agar added to inhibit corrosion.

${ }^{1}$ Department of Scientiflc and Industrial Research : Food Investigation. Special Report No. 41: The Freezing, Storage and Transport of New Zealand Lamb. By Dr. Ezer Griffiths, Dr. J. R. Vickery and N. E. Holmes. Pp. $\mathrm{x}+178+19$ plates. $78.6 d$. net.

2 Department of Scientific and Industrial Research: Food Investigation. Special Report No. 42: The Yellowing of the Abdominal Fa of Frozen Rabbits. By Dr. J. R. Vickery. Pp. iv +27. 6d. net.

Department of Scientific and Industrial Research. Index to the Literature of Food Investigation. Vol. 4, No. 1, March. Compiled by Agnes Elisabeth Glennie. Pp. iv +135 . 28. $6 d$. net.

(London: H.M. Stationery Office, 1932.)

\title{
New Tank at the National Physical Laboratory
}

$\mathrm{O}^{\mathrm{N}}$ November 18, in the presence of a large gathering of naval architects, shipowners, shipbuilders, engineers and others, Mr. Stanley Baldwin, Lord President of the Council, opened the New Tank at the William Froude Laboratory, which forms a part of the National Physical Laboratory, Teddington. The New Tank has

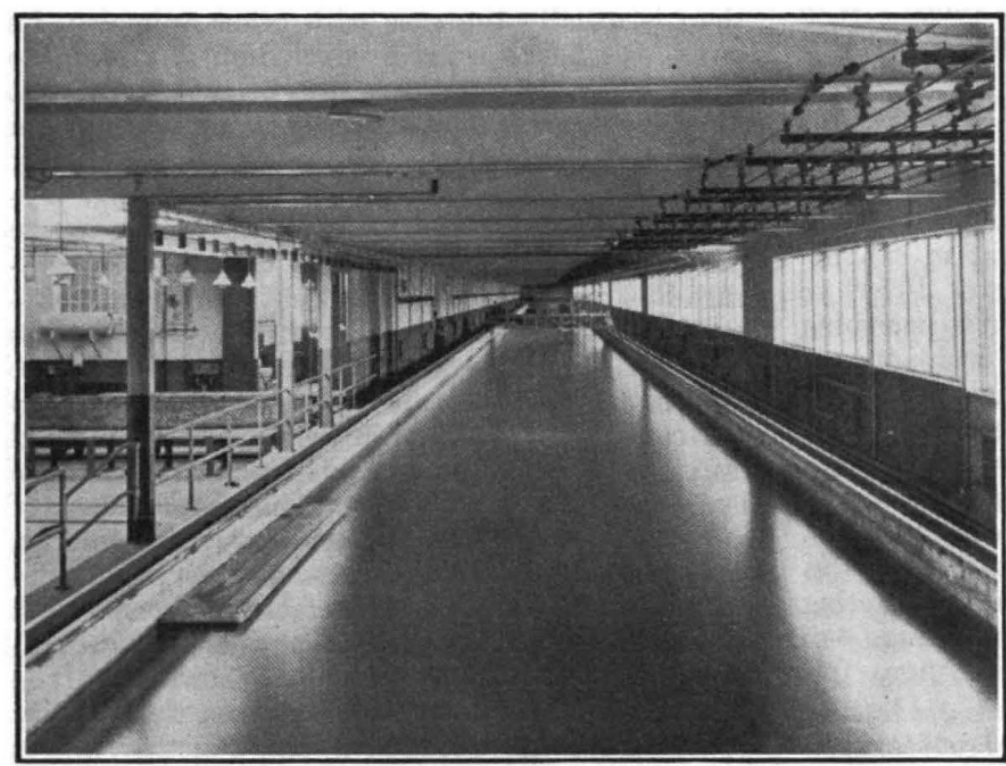

FIG. 1. The New Tank at the William Froude Laboratory

been built by the Government at a cost of $£ 45,000$ to meet the increased demand for model tests of ships' hulls, propellers and rudders, and like the Alfred Yarrow Tank, will be used in connexion with work for ships of the mercantile marine.

Referring to the work done in the Tank given to the Laboratory in 1910 by Sir Alfred Yarrow,
Mr. Baldwin remarked that, in 1928-29 it had become impossible, though the whole staff of the Laboratory was working overtime, to comply with all the requests made for assistance by shipbuilding firms. During the years 1927-1930, 188 designs of hulls were tested in the Tank and it was possible to show how designs could be improved in no fewer than 114 cases. Among the results obtained, and adopted in the shipbuilding industry largely through comprehensive researches in the Yarrow Tank are the introduction of the 'cruiser stern' on ordinary mercantile vessels, the introduction of 'aerofoil' types of propellers, the change of rake now common in single-screw ships and the use of a central fin on this type of ship to control inflow into the propeller.

At the conclusion of his address, Mr. Baldwin went aboard the carriage of the New Tank and watched an experiment with the new equipment for testing the efficiency of propellers working in open water. Visitors present also had an opportunity of witnessing this and other demonstrations. A number of model hulls together with their recording apparatus were on exhibition, and with these were the drawings of the projected Pro-

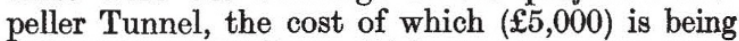
defrayed by Sir James Lithgow.

The New Tank (Fig. 1) consists of a monolithic ferro-concrete water basin $678 \mathrm{ft}$. long over all and $20 \mathrm{ft}$. wide at the water surface. The depth

No. 3291, VoL. 130] 
of water is $9 \mathrm{ft}$. for a distance of $446 \mathrm{ft}$. From this point the bottom slopes upwards gently for $36 \mathrm{ft}$. to the shallow end, $177 \mathrm{ft}$. long, where the depth of water is only $2 \mathrm{ft}$. The tank bottom and walls, the foundations of which are entirely separate from those of the building, were built in $20 \mathrm{ft}$. sections separated by $3 \mathrm{ft}$. gaps, which were filled in after the adjacent sections had set and hardened.

The carriage (Fig. 2) consists of a light frame structure of mild steel weighing approximately $10,000 \mathrm{lb}$. including its equipment. The rails on which it runs are $20 \frac{1}{2} \mathrm{ft}$. centre to centre. They were machined top and bottom before being fixed to the castiron longitudinal sleepers, and are exactly parallel with the surface of the water. The carriage is driven by two 56 h.p. electric motors at speeds of $2-30 \mathrm{ft}$. a second, and is brought to rest by slipper-brakes and a brake rail, operated by compressed air on the principle of the Westinghouse brake.

The control gear for the carriage is located at the side of the Tank, but should the current fail during the course of an experiment, the carriage is automatically brought to rest. In the central portion of the carriage there is an open well about $10 \mathrm{ft}$. by $4 \mathrm{ft}$. within which the testing apparatus is erected; just beneath this well the model floats in the water. In some cases the recording apparatus is placed in the models themselves, which are, of course, as usual, made of wax.

The history of experiments in Great Britain on the resistance of ships' models goes back to the pioneering work of Mark Beaufoy (1764-1827), David Napier (1790-1869), the Scotts of Greenock, the Halls of Aberdeen and others, but, as Elgar said in his Forrest Lecture in 1907 : "The practical solution of the speed problem was effected by the late Mr. William Froude when he discovered the law of similitude or comparison which enables the resistance of a model, as ascertained by experiment, to be used for calculating the resistance of a model upon a different scale, or that of a full-sized ship of similar form."

Froude was born in Devonshire on November 28, 1810, and died at Simon's Town, South Africa, on May 4, 1879. After graduating at Oxford, he spent several years on railway construction and served under Brunel on the Bristol and Exeter Railway. In 1856, when Brunel was engaged with the building of the steamship Great Eastern, he asked Froude to investigate the motion of a ship among waves. From that inquiry Froude was led on to the study of problems akin to it, and through his experiments on towed models, the Admiralty, in spite of many adverse opinions, in 1870 constructed the historic experimental tank at Chelston Cross, Torquay, where Froude had settled. To-day there are more than a score of experimental tanks in existence and every one of them is a monument to the genius and work of Froude. The investigations carried out by Froude at Torquay, and later on at Haslar by his son, R. E. Froude (1846-1924) nearly all related

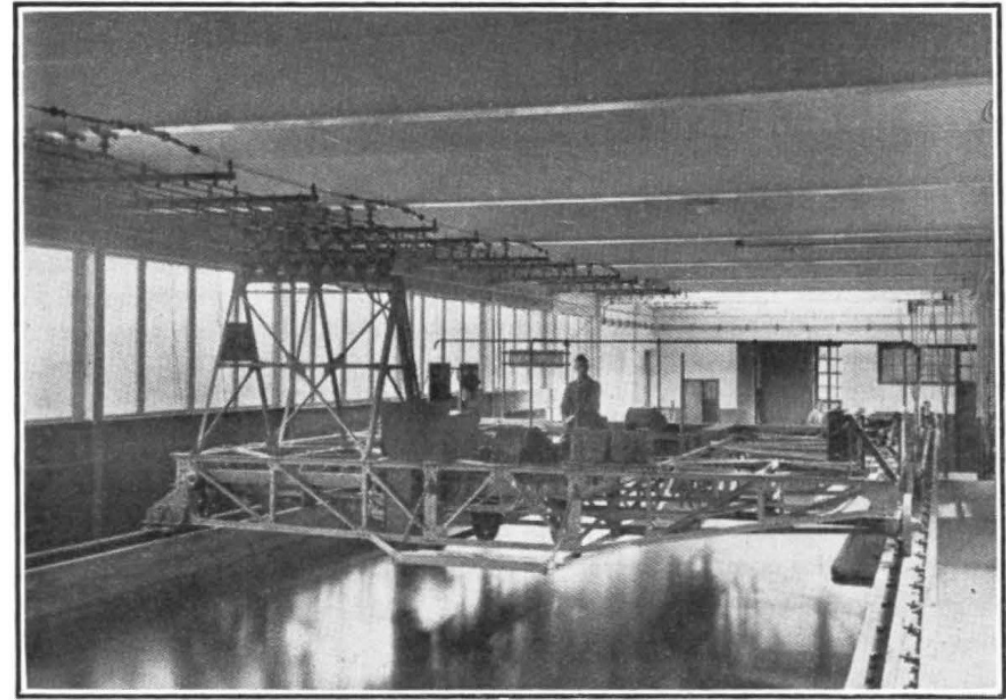

FIG. 2. The carriage of the New Tank

to warships. But just as the credit for the inauguration of the first official tank belongs to Froude, so the credit for the construction of the first tank by private enterprise belongs to William Denny (1847-1887), whose tragic death at forty years of age removed one of the foremost advocates of model experiments. In 1875 Denny sent Froude the lines of the S.S. Merkara, built at the Leven shipyard, Dumbarton, to enable him to make trials with a model for comparison with those already.obtained with the ship herself. With permission of the Admiralty, this was carried out. Six years later, Denny began the construction of a tank at the Leven shipyard and this is now the oldest in existence devoted to mercantile work. On its facade it has borne for 49 years an inscription to Froude "the greatest of experimenters and investigators in hydrodynamics".

In his papers, his speeches and his letters, Denny did all within his power to convince his fellow shipbuilders of the utility of experimental tanks, and in 1884 wrote: "The truth is that of all the problems about a steamship the only one at the present moment incapable of being solved by à priori methods in extreme cases is that of speed and power. No ability and no training will enable even the most skilful naval architect to overcome the want of an experimental tank in coping with these questions."

Denny's was often a 'voice crying in the wilderness', but to-day there are few shipbuilders or shipowners who do not realise the value of the work done in such tanks as that opened by Mr. Baldwin, and none whose work is not influenced by it.

No. 3291, VoL. 130] 